\title{
GEOMETRIC NONLINEAR VIBRATION ANALYSIS OF STEEL FRAMES WITH SEMI-RIGID CONNECTIONS AND RIGID-ZONES
}

\author{
Vu Quoc Anh, NGHiem Manh Hien \\ Faculty of Civil Engineering - Ha Noi Architectural University
}

\begin{abstract}
To obtain an accurate insight into the behavior of the most realistic steel frames, joint flexibility should be allowed for in the analysis. So far, most research work is concentrated on the linear and geometric nonlinear static analysis of steel frames with flexible connections. Very few papers were contributed to the dynamic and vibration analysis of these types of frames. This paper proposes a numerical method for geometric nonlinear vibration analysis of frames with semi-rigid connections and rigid-zones. The effect of initial stress due to the applied load is accounted for in the suggested method, which is believed to be more general than the existing methods and does not involve complex calculations.
\end{abstract}

\section{Introduction}

In the vibration check of slender frames, the stiffness cannot be assumed to be constant at all load levels, because of the change of stiffness arisen from the presence of initial axial stress. The presence of an axial load affects the stiffness of a beam-column. This effect can be included via the geometric stiffness matrix or by the stability function. It in turn affects the dynamical characteristics of a beam-column system. This article is aimed at the study of the effect of an axial load on the vibration of frames with semi rigid connections and rigid-zones. These analyses have been applied to steel buildings with typical types of connections. In order to qualify the connection stiffness, the computer program has been created. The so obtained result illustrating that the consideration of semi-rigid behavior in connections could give a more realistic prediction for the geometric nonlinear vibrations of steel structures.

2. Dynamic equations, the stiffness matrix and mass matrix of the beam element with semi-rigid connections and rigid-zones

To incorporate the connection rigidity into the member stiffness, it is a common practice to model the semi-rigid connection as massless and zero length rotational spring. Although semi-rigid connections exhibit nonlinear response characteristics throughout their whole loading history, it is generally accepted that under service loading conditions the semi-rigid connections can be assumed to behave linearly.

Equations that govern the dynamic response of a structure or medium will be derived by requiring the work of external forces to be absorbed by the work of internal, 
inertial, and viscous forces for any small kinematically admissible motion (i.e., any small motion that satisfies both compatibility and essential boundary conditions) [2], [3]. For a single element, this work balance becomes

$$
\begin{aligned}
\int_{V_{e}}\{\delta \varepsilon\}^{T}[D]\{\varepsilon\} d V & +\left\{\delta u_{k}\right\}^{T}\left[k_{k}\right]\left\{u_{k}\right\}+\int_{V_{e}}\{\delta u\}^{T} \rho\{\ddot{u}\} d V \\
& +\int_{V_{e}}\{\delta u\}^{T} k_{d}\{\dot{u}\} d V=\int_{V_{e}}\{\delta u\}^{T}\{q\} d V
\end{aligned}
$$

where $\{\delta u\}$ and $\{\delta \varepsilon\}$ are respectively small arbitrary displacements and their corresponding strains, $[D]$ is the material property matrix, $\left[k_{k}\right]$ is the stiffness matrix of the springs, $\left\{\delta u_{k}\right\}^{T}$ are the small displacement of the springs, $\{q\}$ are body forces, $\rho$ is the mass density of the material, $k_{d}$ is a material-damping parameter analogous to viscosity, and volume integration is carried out over the element volume $V_{e}$.

Using usual notation, we have for displacement field $\{u\}$ (which is a function of both space and time) and its first two time derivatives

$$
\begin{array}{rlrl}
\{u\}=[N]\{x\} ; & \{\dot{u}\}=[N]\{\dot{x}\} ; & \{\ddot{u}\}=[N]\{\ddot{x}\} \\
\{x\}=[T]\{X\} ; & \{\dot{x}\}=[T]\{\dot{X}\} ; & & \{\ddot{x}\}=[T]\{\ddot{X}\} \\
\{X\}=[e]\left\{X^{*}\right\} ; & \{\dot{X}\}=[e]\left\{\dot{X}^{*}\right\} ; & & \{\ddot{X}\}=[e]\left\{\ddot{X}^{*}\right\} \quad \\
\{u\}=[N][T][e]\left\{X^{*}\right\} ; & \{\dot{u}\}=[N][T][e]\left\{\dot{X}^{*}\right\} ; & \{\ddot{u}\}=[N][T][e]\left\{\ddot{X}^{*}\right\}
\end{array}
$$

In Eqs. (2.2), shape functions [N] are functions of space only and nodal d.o.f. $\{x\}$, $\{X\},\left\{X^{*}\right\}$ are functions of time only, $[T]$ and $[e]$ are transformation matrices [6]. Thus Eqs. (2.2) represent a local separation of variables. Combination of Eqs. (2.1) and (2.2) yields 


$$
\begin{aligned}
& \left\{\delta X^{*}\right\}^{T}\left[\int_{V_{e}}[e]^{T}[T]^{T}[B]^{T}[D][B][T][e] d V\left\{X^{*}\right\}+[e]^{T}([I]-[T])^{T}\left[k_{k}\right]([I]-[T])[e]\left\{X^{*}\right\}\right. \\
& \left.+\int_{V_{e}}[e]^{T}[T]^{T}[N]^{T} \rho[N][T][e] d V\left\{\ddot{X}^{*}\right\}+\int_{V_{e}}[e]^{T}[T]^{T}[N]^{T} k_{d}[N][T][e] d V\left\{\dot{X}^{*}\right\}\right] \\
& =\left\{\delta X^{*}\right\}^{T}\left[\int_{V_{e}}[e]^{T}[T]^{T}[N]^{T}\{q\} d V\right]
\end{aligned}
$$

Since $\left\{\delta X^{*}\right\}$ is arbitrary, $\mathrm{Eq}(2.4)$ can be written as

$$
[M]\left\{\ddot{X}^{*}\right\}+[C]\left\{\dot{X}^{*}\right\}+[K]\left\{X^{*}\right\}=\left\{F^{*}\right\}
$$

Strictly speaking, the stiffness of a framed structure is not constant but dependent on the load. This effect can be included in the instantaneous or incremental equilibrium equations via the adoption of the geometric stiffness matrix. Dynamic analysis of structure with consideration of geometric nonlinear leads to the equation

$$
[M]\left\{\ddot{X}^{*}\right\}+[C]\{\dot{X}\}+\left([K]+\left[K_{\sigma}\right]\right)\left\{X^{*}\right\}=\left\{F^{*}\right\}
$$

where: $[K],\left[K_{\sigma}\right],[M],[C]$ are the stiffness matrix, geometric stiffness matrix, mass matrix and damping matrix of the element with semi-rigid connections and rigidzones, where $\left[K_{\sigma}\right]$ is the geometric stiffness matrix depending on the load level; $\left\{F^{*}\right\}$ are external load vectors; $\left\{X^{*}\right\},\left\{\dot{X}^{*}\right\},\left\{\ddot{X}^{*}\right\}$ are the displacement vectors, velocity vectors and acceleration vectors of the element with semi-rigid connections and rigid-zones.

The stiffness matrix, geometric stiffness matrix, mass matrix and external load vectors of the beam element with semi-rigid connections and rigid-zones are defined as:

$$
\begin{aligned}
{[K] } & =\int_{V_{e}}[e]^{T}[T]^{T}[B]^{T}[D][B][T][e] d V+[e]^{T}([I]-[T])^{T}\left[k_{k}\right]([I]-[T])[e] \\
& =[e]^{T}[T]^{T}\left[\int_{V_{e}}[B]^{T}[D][B] d V\right][T][e]+[e]^{T}([I]-[T])^{T}\left[k_{k}\right]([I]-[T])[e] \\
& =[e]^{T}\left([T]^{T}[k][T]+([I]-[T])^{T}\left[k_{k}\right]([I]-[T])\right)[e]=[e]^{T}[k][T][e],
\end{aligned}
$$

where

$$
[k]=\int_{V_{e}}[B]^{T}[E][B] d V=\frac{E J}{L^{3}}\left[\begin{array}{cccc}
12 & 6 L & -12 & 6 L \\
6 L & 4 L^{2} & -6 L & 2 L^{2} \\
-12 & -6 L & 12 & -6 L \\
6 L & 2 L^{2} & -6 L & 4 L^{2}
\end{array}\right]
$$




$$
\left[k_{k}\right]=\left[\begin{array}{cccc}
0 & 0 & 0 & 0 \\
0 & k_{1} & 0 & 0 \\
0 & 0 & 0 & 0 \\
0 & 0 & 0 & k_{2}
\end{array}\right]
$$

We obtain the geometric stiffness matrix of semi-rigid connection and rigid zones as [6]:

$$
\left[K_{\sigma}\right]=[e]^{T}[T]^{T}\left[k_{\sigma}\right][T][e]
$$

where

$$
\left[k_{\sigma}\right]=\frac{P}{30 L}\left[\begin{array}{cccc}
12 & 6 L & -12 & 6 L \\
6 L & 4 L^{2} & -6 L & 2 L^{2} \\
-12 & -6 L & 12 & -6 L \\
6 L & 2 L^{2} & -6 L & 4 L^{2}
\end{array}\right]
$$

and the mass matrix:

$$
\begin{aligned}
{[M] } & =\int_{V_{e}}[e]^{T}[T]^{T}[N]^{T} \rho[N][T][e] d V \\
& =[e]^{T}[T]^{T}\left[\int_{V_{e}}[N]^{T} \rho[N] d V\right][T][e]=[e]^{T}[T]^{T}[m][T][e],
\end{aligned}
$$

where $\{\varepsilon\}=[B]\{x\} ;[B]=\frac{d}{d x^{2}}[N] ; A$ is the cross-sectional area;

$$
[m]=\int_{V_{e}}[N]^{T} \rho[N] d V=\frac{\rho A L}{420}\left[\begin{array}{cccc}
156 & 22 L & 54 & -13 L \\
22 L & 4 L^{2} & 13 L & -3 L^{2} \\
54 & 13 L & 156 & -22 L \\
-13 L & -3 L^{2} & -22 L & 4 L^{2}
\end{array}\right]
$$

and finally the external load vector:

$$
\left\{F^{*}\right\}=[e]^{T}[T]^{T}\{f\} ; \quad \text { where } \quad\{f\}=\int_{V_{e}}[N]^{T}\{q\} d V .
$$

The transformation matrixes $[e]$ and $[T]$ are created as $[5,6]$

\section{Numerical examples for verfication}

In the computer analysis of frames taking into account the nonlinear effect due to the change of stiffness by the initial stress, free dynamic vibration-real eigenvalues are defined [4]. If no damping or forcing terms exist in the dynamic problem of Eq. (2.6) this is reduced to

$$
[M]\left\{\ddot{X}^{*}\right\}+\left([K]+\left[K_{\sigma}\right]\right)\left\{X^{*}\right\}=\{0\},
$$


a general solution of such an equation is written as

$$
\left\{X^{*}\right\}=\left\{\bar{X}^{*}\right\} \sin (\omega t+\psi) \text {. }
$$

Substituted (3.2) into (3.1) we find that $\omega$ can be determined from

$$
-\omega^{2}[M]\left\{\bar{X}^{*}\right\}+\left([K]+\left[K_{\sigma}\right]\right)\left\{\bar{X}^{*}\right\}=\{0\} .
$$

The Eq. (3.3) is used to determine the geometric nonlinear natural frequencies of the beam element with semi-rigid connections and rigid-zones.

The develop analysis was numerically implemented through a computer program written by Pascal language, which was tested for efficiency and reliability. The input is methodically and economically grouped into data files with very little time and effort required for their preparation. Most features broadening the scope of the analysis have been transferred to the computer code.

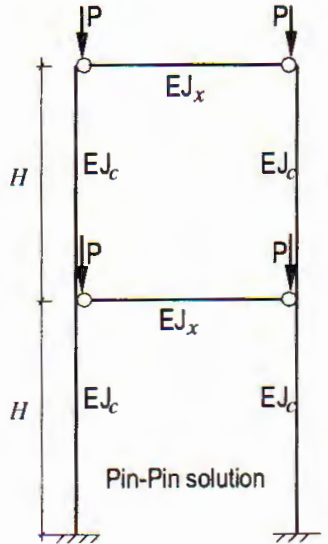

a)

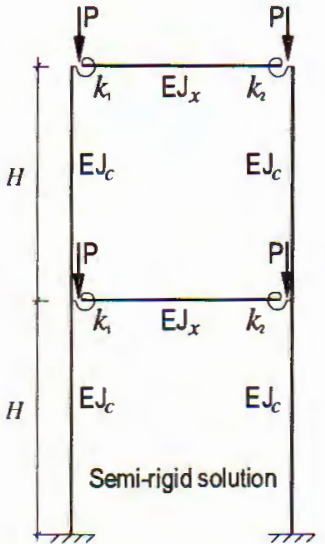

b)

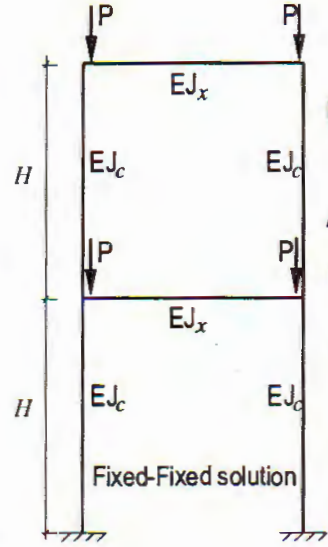

c) $+\quad L$

$E=30000 \mathrm{kip} / \mathrm{in}^{2}$ $=21091327376.5 \mathrm{~kg} / \mathrm{m}^{2}$

$A=17.63 \mathrm{in}^{2}=0.0114 \mathrm{~m}^{2}$

$\beta=\frac{P}{P_{i n}} \quad \alpha=\frac{k}{i_{x}}=\frac{\mathrm{L} k}{\mathrm{EJ}_{x}}$

$\rho=7.372122$ kips $^{2} /$ in $^{4}$

$=803.338 \mathrm{kgs}^{2} / \mathrm{m}^{4}\left(\mathrm{KG} / \mathrm{m}^{3}\right)$

$J_{C}=J_{x}=984 \mathrm{in}^{4}=0.0004096 \mathrm{~m}^{4}$

$\mathrm{H}=240 \mathrm{in}=6.096 \mathrm{~m}$ $L=480 \mathrm{in}=12.192 \mathrm{~m}$

Fig. 1. Vibration analysis of portal frames with various spring stiffness

Several plane frames are investigated using the program to demonstrate the validity and effectiveness of the dynamic analysis for semi-rigid frames. The table 2 illustrated for $\beta=P / P_{T h}=0$ to 0.999 and $\alpha=0.001$ to $\alpha=1000$ respectively with simple connections and rigid connections, for semi-rigid connections $k_{1}=k_{2}=k$.

Table 1. Mode 1-Natural frequency $\omega$ without consideration of geometric nonlinear

Joint type

Theory [1]

Article computer code

Sap 2000
Pin-pin solution

12.745

12.281
Fixed-fixed solution

27.620

27.579

27.096 
Table 2. Mode 1-Natural frequency $\omega$ with consideration of geometric nonlinear

\begin{tabular}{|c|c|c|c|c|c|c|c|c|}
\hline$\beta=$ & Pin- & Ser & i-rigid & olution-s & oint Sti & ness $\alpha$ & $k /$ & \\
\hline$P / P_{T h}$ & Pin & $\overline{0.001}$ & 0.01 & 0.1 & 1 & 10 & 1000 & Fixed \\
\hline 0 & 12.745 & 12.75 & 12.816 & 13.418 & 17.291 & 24.563 & 27.540 & 27.58 \\
\hline 0.1 & 12.10 & 12.10 & 12.164 & 12.735 & 16.409 & 23.303 & 26.130 & 26.17 \\
\hline 0.2 & 11.41 & 11.42 & 11.473 & 12.012 & 15.477 & 21.971 & 24.638 & 24.67 \\
\hline 0.3 & 10.68 & 10.68 & 10.737 & 11.241 & 14.483 & 20.552 & 23.050 & 23.08 \\
\hline 0.4 & 9.89 & 9.90 & 9.945 & 10.412 & 13.414 & 19.028 & 21.343 & 21.37 \\
\hline 0.5 & 9.03 & 9.04 & 9.082 & 9.509 & 12.250 & 17.371 & 19.486 & 19.51 \\
\hline 0.6 & 8.08 & 8.09 & 8.127 & 8.509 & 10.962 & 15.537 & 17.432 & 17.46 \\
\hline 0.7 & 7.00 & 7.01 & 7.042 & 7.373 & 9.497 & 13.456 & 15.100 & 15.12 \\
\hline 0.8 & 5.72 & 5.72 & 5.753 & 6.023 & 8.489 & 10.987 & 12.331 & 12.35 \\
\hline 0.9 & 4.05 & 4.05 & 4.070 & 4.261 & 5.489 & 7.769 & 8.722 & 8.73 \\
\hline 0.999 & 13 & 0.128 & 0.129 & 0.135 & 0.174 & 0.246 & 0.276 & 0.276 \\
\hline
\end{tabular}

It can be seen in table 2 that the variation of the natural frequency is considerable when the joint stiffness changes. Consequently, the ignorance of this joint flexibility may generally lead to an unacceptable error in the analysis for many types of structures.

As can be seen in table 2, an axial force alters the natural frequency significantly when the force is large. If the axial load is in tension, the frequency of the member will be increased and vice versa. When the load is close to the Euler's buckling load, the frequency will tend to zero, indicating an unstable equilibrium state where frequency will be very low.

\section{Conclusions}

The results of these analyses are believed to represent a rather complete picture on the vibration behavior of steel frames with semi-rigid connections and rigid-zones by various types of joints. Generally speaking, the extent of the influence due to the geometric stiffness and joint flexibility can be inspected by studying the relationship between various matrices in equation (3.3). The proposed method adopts a shape function with springs and rigid-zones at both ends and thus the principle of the total potential energy can be applied directly to obtain the element matrices.

The effect of axial load on the natural frequency of a structure depends on the magnitude of the change of the member stiffness by the load. For slender structures subjected to high axial load, this effect is significant and vice versa. In general, if column of medium slenderness are designed without the consideration of axial load effect, the frequency of structure will be over-estimated.

The computer program has been written for the geometric nonlinear vibration analysis of steel frames with semi rigid connections and rigid-zones in this study 
based on the above derivations. The validity of the program is substantiated by the test cases in table 1.

Examples on the linear and geometric nonlinear vibration analysis of steel frame with semi-rigid connections and rigid-zones are given to illustrate the application and the accuracy of the suggested techniques.

\section{REFERENCES}

1. James M. L., Smith G. M., Wolford J. C. Vibration of Mechanical and Structural Systems with Microcomputer Applications, Second Edition, Harper Collins College Publisher 1994.

2. Richard H. Gallagher. Finite Element Analysis Fundamental, Prentice-Hall, INC., Englewood Cliffs, New Jersey 1975.

3. Cook R. D., Malkus D. S. and Plesha M. E. Concepts and Applications of Finite Element Analysis, Third Edition, John Wiley and Sons, Inc, ISBN 0-471-84788-7, 1989

4. Zienkiewicz O. C. CBE, FRS and Taylor R. L. The Finite Element Method, Fourth Edition, Volume 1, Published by Mc GRAW-HILL Book Company Europe, ISBN 0-07-064174 - 8, 1989.

5. Nguyễn Trâm, Vũ Quốc Anh, Nghiêm Mạnh Hiến. Vibration Analysis of Steel Frames with Semi-rigid Connections and Rigid-Zones, The proceeding of the National Conference on Engineering Mechanics, Viet Nam National University Publishing House, Hanoi, October 12-13/2001.

6. Vũ Quốc Anh. Stability analysis of steel frames with semi-rigid connections and rigid zones by using $P$-Delta effect, Viet nam Journal of Mechanics, Vol 24, No 1, 2002.

Received November 25, 2002

DAO ĐÔNGG KHUNG THÉP CÓ NÚT CƯNG VÀ LIÊN KẾT ĐÀN HỒI XÉT ĐẾN SƯ LÀM VIỆC PHI TUYẾN HİNH HOOC

Theo phương phân tích dao động thông thường độ cứng của hệ kết cấu là hằng số, nhưng thực tế độ cứng của hệ còn phụ thuộc vào đặc tính của tải trọng tác dụng lên hệ. Bài báo đã sử dưng phương pháp phần tử hữu hạn để khảo sát độ đàn hồi của liên kết và sự làm việc phi tuyến hình học của hệ ảnh hưởng thế nào đến tần sổ dao động riêng của khung. Cách tính trên được xây dựng dựa trên mô hình làm việc sát thực tế hơn của hệ kết cấu vì đã xét được sự làm việc phi tuyến hình học và độ đàn hồi của liên kết ánh hương đến bài toán động lực học công trình. Về mă̆t ứng dụng, tần số dao động riêng của hệ kết cấu hoặc một phần của hệ kết cấu khi thiết kế cấu tạo phải khác với tần số dao động kích thích để tránh hiện tượng cộng hưởng. Do đó, việc dự báo chính xác tần số dao động riêng của công trình là một bước quan trọng trong quá trình thiết kế kết cấu. 